\section{Imagem e pesquisa na Amazônia}

\section{Por Rubens da Silva Ferreira}

Mestre em Planejamento do Desenvolvimento pela Universidade Federal do Pará. Técnico do Instituto do Patrimônio Histórico e Artístico Nacional (rubenspa@yahoo.com / rubens@iphan.gov.br)

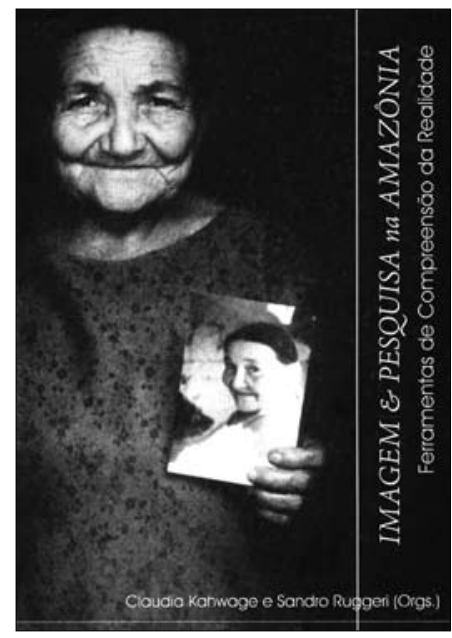

KAHWAGE, Claudia; RUGGERI, Sandro (Orgs.). Imagem e pesquisa na Amazônia: ferramentas de compreensão da realidade. Belém: NAEA; Alves, 2007. 224p. il.

O processo de geração do conhecimento em contextos acadêmicos envolve uma diversidade de atividades sistemáticas compreendidas entre o momento da concepção do que se quer pesquisar e a socialização dos resultados da pesquisa à sociedade. Tal como se tem observado na tradição da comunicação científica, notadamente a partir do desenvolvimento da imprensa nos anos de 1400, o texto escrito se impôs como ferramenta dominante e legítima de expressão desse tipo de conhecimento. Somente nos séculos XVIII e XIX as imagens começam a despontar como estratégia comunicativa para explicar o mundo em sua dimensão visível, mas sem a pretensão de solapar a palavra escrita; ao contrário disso, texto e imagem passam gradativamente a ser tomados de maneira complementar e inter-relacional para dar conta do real concreto.

Nesta perspectiva, Claudia Kahwage - bióloga e antropóloga associada do Núcleo de Altos Estudos Amazônicos (NAEA/UFPA) - e Sandro Ruggeri - ator e mestre em Planejamento do Desenvolvimento (PLADES/NAEA)
- organizaram, em 2004, o seminário "Imagem e pesquisa: ferramentas de compreensão da realidade amazônica", com o propósito de intercambiar reflexões e experiências sobre o uso acadêmico da imagem na Amazônia paraense, qual fosse a fotografia, o vídeo ou o cinema. Desse evento resultou o livro homônimo, que congrega oito autores de diferentes formações e graus acadêmicos, cada um analisando o potencial do recurso imagético sob enfoque próprio. Em seu conjunto, a produção dos autores eleva a imagem ao status de recurso informativo seminal para a pesquisa científica, tal como Margaret Mead, Gregory Bateson e Bronislaw Malinowski imprimiram aos estudos antropológicos que ajudaram a instituir a Antropologia Visual como disciplina no século $X X$

O capítulo de abertura é assinado pela Ph. D. em Antropologia, Ligia T. L. Simonian. Em "Uma relação que se amplia: fotografia e ciência sobre e na Amazônia", Simonian refaz o percurso da imagem no desenvolvimento da ciência entre os séculos XIX e XXI, procurando situar quem produziu e o que tem sido produzido nessa região brasileira marcada por uma biosociodiversidade emblemática. Desse modo, Simonian reflete inicialmente sobre a iconografia produzida pelos viajantes, naturalistas, ensaístas, cartógrafos e outros produtores de imagens num período muito anterior ao surgimento da fotografia; e, após o surgimento desta, são rememoradas as experiências de produções fotográficas a serviço da ciência na Amazônia, tal como fizeram o botânico Jacques Huber e o etnógrafo Theodor Koch-Grünberg, o primeiro de origem suíça e o segundo, alemão.

As vivências de Simonian na produção fotográfica de caráter documental são contempladas à luz das contribuições teóricas da antropologia, precisamente da antropologia visual, por meio da qual tem introduzido discussões sobre o uso da imagem em pesquisas na disciplina Metodologia Científica, ministrada por ela no NAEA/UFPA. Neste ponto, a autora apresenta suas experiências como fotógrafa nos estudos sobre gênero, meio ambiente, migrações transnacionais, populações indígenas e comunidades tradicionais na Amazônia brasileira, por meio das quais, literalmente, mostra - no

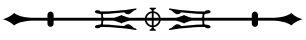


mais puro sentido malinowskiano - tais realidades em seus aspectos sensíveis, desafiantes e contraditórios. A estes estudos são acrescidos trabalhos contemporâneos de autorias diversas, os quais têm colocado a imagem na base da produção científica regional. Entretanto, Simonian alerta para os limites do uso da fotografia na ciência, precisamente no que concerne à disposição do(s) indivíduo(s) em deixarse fotografar ou não, apontando para a necessidade de uma ética da imagem na pós-modernidade.

Em "Impressões de um lugar", o arquiteto e fotógrafo Alexandre Romariz Sequeira faz uma exposição teórica e fundamentalmente descritiva de sua vivência junto aos moradores da vila de pescadores de Nazaré do Mocajuba, situada no município de Curuçá, Pará. $\bigcirc$ contato do pesquisador com tal realidade aconteceu através de uma bolsa de apoio à pesquisa concedida pelo Instituto de Artes do Pará (IAP). Munido de uma câmera fotográfica Nikon FM-2, o autor lançou-se em uma experiência sensorial que o inspirou na montagem da instalação "Impressões de um lugar", exibida em 2004, na qual os moradores de Nazaré do Mocajuba tiveram seus retratos em tamanho natural impressos em tecidos presentes no cotidiano das populações amazônicas. Seguindo o referencial da fenomenologia, da Teoria da Percepção e da semiótica, Sequeira consegue produzir um texto sobre a imagem, no qual ciência e arte são eficientemente articuladas para representar a essência de um lugar repleto de memórias e significados para os indivíduos fotografados.

As possibilidades do audiovisual para a pesquisa científica é a questão que norteia a análise do turismólogo e doutor em comunicação Silvio Lima Figueiredo. No texto "Imagem e pesquisa: experiência de registros fílmicos da cultura tradicional/popular", o autor discute, após situar os marcos diferenciais entre filmes científicos e documentários, o desafiante dilema entre pesquisador/autor e forma/ conteúdo que se impõe à produção audiovisual de interesse acadêmico. Após os direcionamentos teóricos, o autor volta-se para a análise de sua produção autoral ("Naza"; "Serra das Andorinhas"; "Arqueologia e educação em Canaã dos Carajás" e "Brincadeira de Mestre"), quase completamente voltada para as manifestações culturais presentes no estado do Pará, a exemplo do Círio de Nazaré, da Marujada, dos cordões de pássaro e dos boisbumbás. Ao final, o documentarista/pesquisador conclui que a realidade captada pela câmera filmadora é em si uma representação, por meio da qual ele procura aproximarse suficientemente das cenas e dos atores no contexto da ritualização das práticas culturais.

Jorane Castro é cineasta com mestrado em Etnometodologia, que escolheu um dos clássicos de Alfred Hitchcock para analisar a imagem cinematográfica. Em "Considerações sobre o olhar: o personagem de L. B. Jefferies em 'Janela Indiscreta', de Alfred Hitchcock", o enredo é apresentado de maneira minuciosa, evocando as características presentes nas 56 produções que consagraram o cineasta britânico, inclusive o hábito de instigar o voyeur cinéfilo ao aparecer em suas próprias películas. Como bem observa Jorane Castro, "Janela Indiscreta" é uma metáfora ao cinema, na qual o personagem Jeff (James Stuart) se confunde com a platéia que a tudo observa no anonimato da escuridão.

Na seqüência, a imagem fotográfica é retomada em estudo por Fábio Horácio-Castro, que coordenou o curso de especialização "Imagem e Sociedade", da Universidade Federal do Pará, e escreve o trabalho "Fotografia, crítica e hermenêutica", apontando elementos para uma crítica da fotografia que se coloca para além da representação. Tomando emprestada a noção de "figural" presente na produção do filósofo francês Jean-François Lyottard, o autor se propõe evidenciar as diferenças das críticas à fotografia no campo semântico, orientadas pela epistemologia ou pela hermenêutica. Destarte, para a crítica epistemológica, a imagem expressa por si o seu poder de enunciação, onde o significado da "coisa" representada é dado a priori. Neste viés, a fotografia é uma representação do real do referente. Para a crítica hermenêutica, por sua vez, o significado é produzido em contextos intersubjetivos, de modo que, ao observador, a imagem oferece um campo de possibilidades

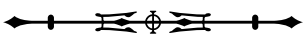


interpretativas reveladoras do processo de experimentação de produção de sentido, o que se aproxima à noção de "figural". Mas, qual seja a escolha do ponto de partida para a crítica da fotografia, Horácio-Castro diz que a imagem é sempre uma forma de conhecer que se configura pelos diferentes modos de ler o mundo.

Sandro Ruggeri também produz reflexões sobre o uso da imagem em "Memento: devanear pelas imagens de Alter-do-Chão". Retomando as fotografias produzidas para a dissertação de mestrado sobre a festa do Çairé - uma celebração do catolicismo popular realizada anualmente em Alter-do-Chão, no município de Santarém, Pará -, Ruggeri agrupa algumas dessas imagens em três categorias. A primeira delas refere-se às fotografias sobre a beleza cênica do rio Tapajós; a segunda categoria contém os registros da festa em si; a terceira, por sua vez, ainda que sem relação ao Çairé, capta o flagrante da luz do crepúsculo se apropriando do espaço de um atelier construído ao modo amazônico, e que chamara a atenção do fotógrafo/pesquisador. Auxiliado por Barthes, Flusser, Gombrich e Semain, Ruggeri procura tratar das pessoas, das coisas e da paisagem tal como foram captadas pela lente da câmera, porém, sem o compromisso de penetrar na essência dos elementos representados. Logo, o texto escrito é colocado a serviço das imagens, sobre as quais o autor lança um olhar livre sobre uma celebração tradicional que tem se atualizado no tempo pelos atores sociais de Alter-do-Chão.

Uma poética da imagem emana de maneira íntima e subjetiva no texto do consagrado escritor paraense e mestre em Teoria Literária e Semiologia, João de Jesus Paes Loureiro. Como esclarecem Claudia Kahwage e Sandro Ruggeri, "Epifanias e encantarias na fotografia de Luiz Braga" foi originalmente elaborado por Paes Loureiro para a comemoração dos 30 anos da produção fotográfica de Luiz Braga, em 2005. Portanto, ele não integra o conjunto de trabalhos apresentados no seminário "Imagem e pesquisa...", agora socializados na forma de livro. Como o próprio título informa, trata-se de uma análise sobre algumas das séries fotográficas do também paraense Luiz Braga, arquiteto e fotógrafo premiado no Brasil e no exterior. Sob o viés do que se tem denominado de fotoetnografia, Luiz Braga tem como traço peculiar a valorização do homem agindo no espaço amazônico, seja ele urbano ou rural, na terra ou nos rios, no centro da capital ou na periferia, trazendo à tona um cotidiano banal que se converte em arte fina pelo olhar sensível do fotógrafo. Por certo, tanto a relevância de uma produção de tal ordem quanto a leitura estética de Paes Loureiro foram determinantes para a decisão de incluir este capítulo no livro.

Claudia Kahwage encerra a seção de textos com o trabalho "'Sexo diferente': corpo, gênero e performance - encontro fotográfico com travestis". Dos contatos mantidos com grupos de travestis que se prostituem na Av. Almirante Barroso, em Belém do Pará, a autora se propõe a compreender a expressividade dos corpos de indivíduos que possuem uma identidade permeada por elementos do universo masculino e feminino. A pesquisa etnográfica, construída a partir da coleta de evidências entre 1998 e 2001, criou as condições para a produção de fotografias nas quais os travestis comunicam uma corporalidade destituída de inibições. Aliás, como observado por Kahwage, os registros fotográficos desses sujeitos são verdadeiros desafios de interpretação, afinal de contas, como seria possível perceber o sexo biológico das pessoas fotografadas? Trata-se de uma mulher ou de um homem? Esse jogo performático de representar papéis de gênero é colocado de modo emblemático pelo próprio informante da autora, o qual já fora travesti no passado e que, na atualidade, se apresenta socialmente como "bicha-boy", trazendo à tona as possibilidades desse grupo fluir entre um gênero e outro. Sem dúvida, os sujeitos selecionados para estudo por Kahwage são propícios para uma abordagem da imagem sob a ótica da antropologia das aparências.

As páginas finais do livro são dedicadas a 30 fotografias de Haydée Márcia Marinho, cientista social com especialização em Imagem e Sociedade. Essas imagens foram produzidas em 2004, quando a autora realizou o

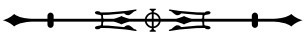


trabalho "Registro e documentação fotográfica das técnicas e tecnologias agrícolas na comunidade de Cumaré", orientado por Claudia Kahwage. Pequenos agricultores, produtos e tecnologias constituem os elementos representados. Todavia, a visualidade desse corpus iconográfico ficou prejudicada pelo tamanho reduzido das fotografias em preto e branco, impressas em dimensões de 1,8 cm x 2,1 cm, o que não permite ao leitor-observador identificar os detalhes do que se quis efetivamente mostrar. Neste ponto, ao relegarem tais imagens às paginas finais do livro, ou seja, após a seqüência de textos, os organizadores parecem reafirmar a supremacia da palavra escrita sobre a imagem no fazer científico, o que não chega a prejudicar o mérito da obra.

Assim, como se pode verificar em "Imagem e pesquisa...", a coletânea de textos ilustrados que sintetiza as experiências, as reflexões, os insights e as perspectivas de autores com diferentes trajetórias acadêmicas constitui contribuição da maior importância para os estudiosos da imagem em sua diversidade de expressão, precipuamente como um dado científico. Em conjunto, esses trabalhos apontam para a necessidade de se ampliar o uso dos recursos fílmicos e fotográficos na produção científica, haja vista o poder informativo e testemunhal da imagem. Nessa perspectiva, a obra parece destinada a um público amplo, formado por artistas, pesquisadores e estudantes nos diferentes domínios do saber, particularmente na Antropologia, Sociologia, História, Lingüística, Ciência da Informação e Artes Visuais. Diante desses aspectos, há que se indicar, igualmente, aos demais interessados nesta temática ainda pouco debatida na academia. 